\title{
O DIREITO DO MAR E SUA EFETIVAÇÃO NO ÂMBITO INTERNACIONAL: UMA ANÁLISE SOBRE A RESPONSABILIDADE POR DANOS CAUSADOS NO AMBIENTE MARINHO
}

\section{THE LAW OF THE SEA A ITS EFFECTIVE IN INTERNATIONAL CONTEXT: AN ANALYSIS OF LIABILITY FOR DAMAGES CAUSED IN THE MARINE ENVIRONMENT}

\author{
${ }^{1}$ Sébastien Kiwonghi Bizawu \\ ${ }^{2}$ Denise Sousa Campos
}

\begin{abstract}
RESUMO
O direito do mar busca dirimir conflitos entre Estados soberanos e favorecer uma ordem jurídica para os mares e oceanos, facilitando as comunicações internacionais e a proteção e conservação do ambiente marinho, efetivando-se a responsabilidade do Estado em caso de danos ao meio marinho. Objetiva-se analisar nesse artigo a Convenção de Montego Bay e a criação do Tribunal do Direito do Mar como ferramenta de resolução pacífica de lides no âmbito internacional. Utilizar-se-á a pesquisa descritiva com método dedutivo, tendo em vista a responsabilidade internacional ambiental do Estado e a necessidade de fortalecer as relações de amizade entre as nações.
\end{abstract}

Palavras-chave: Responsabilidade, Danos ao ambiente marinho, Tribunal internacional do direito do mar

\begin{abstract}
The Law of the Sea seeks to settle conflicts between sovereign states and encourage a legal order for the seas and oceans, making international communications and the protection and conservation of the marine environment, making effective the state's responsibility in case of damage to the marine environment. The objective is to analyze the UNCLOS and the creation of the Law of the Sea Tribunal as peaceful resolution tool labors internationally. Use shall be descriptive research with deductive method, with a view to environmental international responsibility of the State and the need to strengthen the friendly relations between nations
\end{abstract}

Keywords: Responsibility, Damage to the marine environment, International tribunal for the law of the sea

\section{INTRODUÇÃO}

1 Professor de Direito Internacional Público e Privado na Escola Superior Dom Helder Câmara. Escola Superior Dom Helder Câmara - ESDHC, Minas Gerais. Brasil - Email: kiwonghi@domhelder.edu.br

2 Mestranda em Direito Ambiental e Desenvolvimento Sustentável da Escola Superior Dom Helder Câmara.

Escola Superior Dom Helder Câmara - ESDHC, Minas Gerais. Brasil - Email: fisiodireito2007@ hotmail.com 
Sabe-se que o Direito regula a atividade humana, tendo o condão de modificar as relações sociais, sempre buscando o bem-estar social e o gozo dos direitos humanos fundamentais em um mundo globalizado e em constante mudança. Os acontecimentos sociais exigem respostas novas do direito enquanto constituição conscienciosa do homem, sempre em movimento. Não há como dissociar o direito da organização da vida em sociedade baseada na observância de princípios e valores.

Desse modo, a aplicação do direito ao caso concreto merece uma atenção especial, pois a lei deve ter o condão especial de regulamentar efetivamente a sociedade em busca da pacificação social, pois o homem não vive sozinho em uma ilha deserta, mas ele está em relação constante com outros indivíduos e vive em uma sociedade com normas, regras e preceitos bem definidos para dirimir conflitos e assegurar a efetiva convivência social assentada na construção de relações harmoniosas entre os povos, evitando-se, portanto, a "lei do mais forte".

Por permitir aos indivíduos de viver em um ambiente equilibrado e seguro, o direito não segue um padrão preestabelecido, estável, ensejando interpretações que variam conforme os domínios da vida social, podendo ser de ordem privada ou pública. A deviniência jurídica abrange a alterabilidade do expressar jurídico bem como o referencial. Observa-se que decisões judiciais estão em constante mudança e a lei está em constante modificação.

Neste contexto não muito explorado, mas de extrema importância e necessidade de abrangência de ações protetivas, surge a responsabilidade ambiental de danos causados ao ambiente marinho no cerne do Direito Internacional Ambiental e seus métodos de efetivação.

O enfoque a ser abordado sobre a responsabilidade Internacional Ambiental será direcionado aos mares, que desde os primórdios da história universal trata-se de um espaço que se destaca ${ }^{1}$ no que condiz ao desenvolvimento econômico mundial.

Com certa frequência, constatam-se situações de poluição em determinados territórios pertencentes a uma soberania provocados por outros Estados que necessitam de intervenção do Direito Internacional do Ambiente seja para fins de averiguação de

\footnotetext{
${ }^{1}$ MARTINS, Eliane M. Octaviano. “Amazônia Azul”: limites e extensão das zonas marítimas sob soberania e jurisdição nacional do Brasil. Meritum - v. 02, no 02, p. 265-279. Jul/dez. 2007. Belo Horizonte.
} 
responsabilidade, sejam para adoção de medidas preventivas ou mesmo métodos de efetivar o cumprimento das obrigações de prevenção e reparação ${ }^{2}$.

Nesse aspecto, o objetivo do presente artigo é analisar a responsabilidade por danos causados no ambiente marinho, regulamentando os meios de efetivação, mais incisivamente a criação do Tribunal Internacional do Direito do Mar pela Convenção de Montego Bay, também conhecida como Convenção das Nações Unidas sobre o Direito do Mar (1982).

Para tanto, o problema delineado consiste na averiguação da Convenção de Montego Bay e se possui mecanismos capazes de dar efetividade na busca da prevenção e reparação de danos ao ambiente marinho com a correta aplicação e interpretação das normas internacionais, ensejando responsabilidade aos Estados causadores do dano.

Para a realização do presente artigo, utilizar-se-á a pesquisa descritiva baseada em levantamento bibliográfico, abrangendo doutrinas, legislações, convenções internacionais, artigos científicos, dados históricos entre outras matérias pertinentes ao tema. A técnica da pesquisa é a teórica, pois se investiga o problema com auxilio da teoria e análise de conteúdo.

Diante deste cenário traçado, surge a necessidade de criar ferramentas que busquem a resolução de conflitos cada vez mais comuns no meio ambiente marinho envolvendo várias soberanias e jurisdição com a devida apuração de responsabilidades, principalmente pela constatação de um meio social em constante ascensão.

\section{DA PROTEÇÃO INTERNACIONAL DO MEIO AMBIENTE}

Bem rememorável, porquanto imperioso apresentar, Bobbio ${ }^{3}$ que ao sedimentar seus ideais com inexcedível clareza na obra "A Era dos Direitos" afirmou que três características o preocupavam no que condiz ao futuro da humanidade em sendo: o aumento incontrolado da população, o aumento célere e insano do poder destrutivo dos armamentos e por fim a crescente e incontrolável devastação ambiental.

Preocupação em ascensão, a proteção internacional ambiental vem atualmente ganhando espaço na história da humanidade, constituindo ainda um dos principais temas em discussão nos ideais internacionais contemporâneos.

\footnotetext{
2 SAMPAIO, Jorge Silva. Do Direito Internacional do Ambiente à responsabilidade ambiental e seus meios de efectivação no âmbito do Direito Internacional. Revista o Direito, ano $146^{\circ}$, v. II, 2013, pp. 1-55.

3 BOBBIO, Norberto. A Era dos Direitos. Tradução: Carlos Nelson Coutinho. Apresentação: Celso Lafer. Rio de Janeiro: Elsevier, 2004 , p. 66.
} 
Retomando ao Século XX, depara-se com a separação do conceito de meio ambiente e ecologia, sendo aquela sistematizada por normas humanas que oscilam segundo o comportamento humano contrário da ecologia que são direcionadas por leis naturais.

Assim, quando as regras são internacionais, tem-se o denominado Direito Internacional do Meio Ambiente, que recebe maior atenção pós-globalização com reflexos em escala mundial.

Segundo conceitua Mazzuoli:

Em suma, pode-se definir O Direito Internacional do Meio Ambiente como a disciplina jurídica das normas internacionais (escritas e costumeiras) de proteção ambiental. De modo mais abrangente, pode-se dizer trata-se de conjunto de regras e princípios criadores de direitos e deveres de natureza ambiental para os Estados, para as organizações internacionais intergovernamentais e, também, para os particulares (indivíduos e organizações privadas). $\mathrm{Na}$ salvaguarda dos direitos inerentes à proteção internacional do meio ambiente, merece destaque a atuação das citadas organizações intergovernamentais (quer globais, regionais, ou sub-regionais) e sua contribuição para a implementação da normativa internacional em questão nos Estados que delas são parte.

No que condiz á proteção internacional do Meio Ambiente, destaca-se a Conferência das Nações Unidas sobre o Meio Ambiente Humano realizada em Estocolmo, em 1972, surgindo a Declaração sobre o Meio Ambiente Humano, que constitui a base filosófica e jurídica relativo ao tema.

Após este impulso, a consciência ambiental foi se alastrando em meios a catástrofes ambientais, o que consequentemente avivou ainda mais os ideais ecológicos da humanidade ${ }^{5}$.

No Brasil, mais especificamente no Rio de Janeiro, na década de 90, ocorreu a Conferência das Nações Unidas sobre Meio Ambiente e Desenvolvimento, denominada de ECO-92, para levantamento de questões atinentes à proteção do meio ambiente ao seu desenvolvimento e, sobretudo, como ferramenta de reafirmação dos princípios internacionais de direitos humanos e sua conjectura com as normas de proteção ao meio ambiente.

Iniciava-se um marco histórico de transformação no entendimento dos Estados relacionado às responsabilidades uns para com os outros e ainda frente às futuras gerações ${ }^{6}$.

\footnotetext{
4 MAZZUOLI, Valério de Oliveira. Direito Internacional Público. 9 ed. rev. ampl. - São Paulo: Editora Revista dos Tribunais, 2015, p.1079.

5 SAMPAIO, op. cit., p. 4: "Enfim, ameaças globais, perda de biodiversidade e a dilapidação da floresta tropical, a explosão demográfica, etc., mostraram uma crescente complexidade e abrangência das causas e efeitos da atividade humana sobre o ambiente".

${ }^{6}$ SAMPAIO, op. cit. p. 5 .
} 
Diferente do abordado na Convenção de Estocolmo, a Conferência do Rio de Janeiro abordou a cooperação, aflorando a perspectiva de que constitui uma conquista da humanidade: a proteção internacional do meio ambiente, afastando as incompatibilidades ideológicas. Segundo Sampaio, é imperioso identificar as funções primordiais do Direito Internacional do Ambiente, citando Birnie e Boyle ${ }^{7}$,

(i) fornecer mecanismos e procedimentos para a negociação de regras e padrões necessários, resolver disputas e supervisionar a implementação e adequação aos tratados e regras costumeiras, e, assim, ajudar a promover a cooperação entre Estados, organizações internacionais, e organizações não governamentais; (ii) regulamentar problemas ambientais, estabelecer padrões e objectivos internacionais comuns para a prevenção e/ou redução dos danos, e promover um processo de elaboração de regras flexível, que permita a adaptação rápida a novos desenvolvimentos tecnológicos e avanços científicos; (iii) estabelecer a reparação ou compensação por danos ambientais sofridos por um Estado ou indivíduo em virtude de danos transfronteiriços; (iv) desenvolver direitos individuais ambientais e a responsabilização por crimes ambientais definidos no Direito Internacional; e (v) harmonizar leis nacionais, tanto num âmbito global como num âmbito regional (União Europeia, por exemplo), tendo em conta que os tratados e outros instrumentos internacionais influenciam a elaboração das leis internas.

Em síntese ao exposto, é possível concluir que o Direito Internacional Ambiental busca de forma direta a tutela do meio ambiente, quando da construção de tratados internacionais.

\section{ESCORÇO HISTÓRICO DO REGRAMENTO INTERNACIONAL DO MAR}

As normas destinadas ao Direito do Mar suscitou, nos últimos anos, uma atenção da comunidade internacional e, abordando este recente interesse, Cardoso preleciona:

$\mathrm{O}$ interesse que tem despertado prende-se com o facto de se ter vindo a adquirir, progressivamente, a consciência de que, paralelamente aos quadros normativos tradicionais formulados a partir do Direito Internacional Público, se deve considerar um conjunto de regras, de práticas e de procedimentos suscetível de proporcionar soluções que permitam uma gestão das áreas oceânicas em consonância com os princípios hoje geralmente aceites nesse âmbito.

\footnotetext{
7 BIRNIE; BOYLE apud SAMPAIO, Jorge Silva. Do Direito Internacional do ambiente à responsabilidade ambiental e seus meios de efetivação no âmbito do Direito Internacional. Revista o Direito, ano 146o, v. II, 2013, p. 7.
} 
Em se tratando de poluição do mar e o Direito Internacional do Meio Ambiente, é por volta da década de 50 que surgem os precedentes no combate à poluição, evidenciando a Convenção de Londres de 1954 que tratava de matéria pertinente à prevenção da poluição do mar por hidrocarbonetos.

O direito do mar constitui uma importante porção do direito internacional público e, por tempos e tempos, seus regramentos foram simplesmente baseados em costumes. Sua estruturação legal recebeu alento com as Nações Unidas em Genebra no ano de 1958, quando emergiu a Convenção sobre o mar territorial e a zona contígua, a Convenção sobre o alto mar, Convenção sobre pesca e conservação dos recursos vivos do alto mar e a Convenção sobre a plataforma continental ${ }^{8}$.

Em 1960 realizou-se a Segunda Conferência das Nações Unidas sobre o Direito do Mar, contando com 88 Estados, objetivando limitar a extensão do mar territorial.

Rousseau desferia críticas quanto à abstração do mar derivado do res communis, pois considerava ser inexistente qualquer concepção condominial, principalmente quando o mar traduzia cenário de conflagração, sendo na acepção deste um res nullius, cabendo às soberanias somente o exercício de certas competências.

Não obstante os esforços despendidos nas Convenções, os princípios ora determinados por tais conferências restaram obsoletos e inócuos para regulamentar as necessidades emergentes relativas à matéria de Direito do Mar 9

Somente para fins elucidativos, nas décadas de 60 e 70 ocorreram vazamentos de óleo no mar de forma vultosa e catastrófica, o que impactou no ideal humano, que passou a desferir maior preocupação ao meio ambiente marinho.

Diante deste cenário se desenvolveram várias convenções no sentido de regulamentar formas de prevenção e de atribuição de responsabilidades sobre os prejuízos desferidos contra o meio ambiente marinho pela ação humana.

\footnotetext{
8 REZEK, José Francisco. Direito Internacional Público. $7^{a}$ Ed. Ver. - São Paulo, Saraiva, 1998, p. 302: "Sucede que esses quatro textos - cuja aceitação não chegou a ser generalizada - produziram-se no limiar de uma era marcada pelo questionamento das velhas normas e princípios: os oceanos já não representavam apenas uma via de comunicação navegatória, própria para alguma pesca e algumas guerras. O fator econômico, tanto mais relevante quanto enfatizado pelo progresso técnico, haveria de dominar o enfoque do direito do mar nos tempos modernos".

9 MAZZUOLI, op cit.
} 
Inicia-se então em dezembro de 1973 a Terceira Conferência das Nações Unidas relativa ao Direito do Mar, que contou com a presença de 164 Estados, incluindo também os Estados não membros da ONU e que decidiu por adotar uma Convenção sobre o Direito do Mar.

A conclusão desta Convenção das Nações Unidas sobre o Direito do Mar ocorreu em Montego Bay, (Jamáica) em 1982, caracterizando um tratado universal, que somente entrou em vigência aos 16 de novembro de 1994, passados o interregno de 01 ano pós-reunião quando 60 Estados aderiram ao instrumento.

Segundo Mattos ${ }^{10}$, a Convenção de Montego Bay ou a Convenção da Jamaica:

\begin{abstract}
Dispõe a Convenção sobre mar territorial e zona contígua, zona econômica exclusiva, plataforma continental, alto-mar, estreitos utilizados para a navegação internacional, estados arquipélagos, ilhas, mares fechados ou semifechados, área, estados sem litoral, proteção e preservação do meio ambiente, investigação científica marinha e solução de controvérsias, além de disposições gerais e disposições finais.
\end{abstract}

De fato, os problemas do Direito do Mar, em qualquer substrato que seja, se interrelacionam por um estreito liame e devem ser tratados como um todo, sendo injustificável, porquanto impossível o estabelecimento de normas que não se comunicam.

O Brasil em 1988 foi um dos signatários da Convenção buscando amoldar seus regramentos internos às normas daquela antes mesmo de sua vigência e então sua obrigatoriedade legislativa.

Um exemplo de diploma legislativo que figura esta adequação interna do direito Brasileiro aos preceitos da Convenção de Montego Bay antes mesmo de sua vigência, é a Lei $\mathrm{n}^{\mathrm{o}} 8.617^{11}$, de 04 de janeiro de 1993, que apresenta disposições sobre o mar territorial, a zona contígua, a zona econômica exclusiva e a plataforma continental.

\footnotetext{
10 MATTOS, Adherbal Meira. Os novos limites dos espaços marítimos nos trinta anos da Convenção das Nações Unidas sobre o Direito do Mar. In: Reflexões sobre a Convenção do Direito do Mar. André Panno Beirão, Antônio Celso Alves Pereira (orgs). Brasília: Funag, 2014. p. $15-66$.

11 Lei 8.617/93 - Dispõe sobre o mar territorial, a zona contígua, a zona econômica exclusiva e a plataforma continental brasileiros, e dá outras providências. Disponível em: <http://www.planalto.gov.br/ccivil_03/LEIS/L8617.htm> Acesso em: 09 set., 2015.
}

Uma das alterações constatadas foi a diminuição da largura do mar territorial de 
200 (duzentas) milhas (Decreto $\mathrm{n}^{\mathrm{o}} 1.098^{12}$, de 25 de março de 1970), para 12 (doze) milhas, assim como delineada nas cartas náuticas de grande escala, ratificadas pelo Brasil.

O Congresso Nacional aprovou por meio do Decreto Legislativo $n^{\circ} 5^{13}$, de 09 de novembro de 1987, a Convenção Montego Bay (Jamaica), que passou a viger no país, por intermédio do Decreto $\mathrm{n}^{\mathrm{o}} 1.530^{14}$, de 22 de junho de 1995.

De fato, a Convenção de Montego Bay sobre o Direito do Mar está no ápice das regras do Direito Internacional do Meio Ambiente, representando então uma consolidação das normas atinentes ao Direito do Mar, abordando de maneira específica a preservação do meio marinho nos artigos 192 a 237 e, entre estes, mais incisivamente nos artigos 207 a 232, traçando preceitos normativos relativos à poluição transfronteiriça ${ }^{15}$.

Nota-se, portanto, um efeito nefasto quanto à poluição transfronteiriça, transformando a ameaça potencial em perigo real com consequências incomensuráveis. Nesse sentido observam Edna Raquel Hogemann e Marcelo Pereira dos Santos (2015):

\begin{abstract}
A globalização tornou as fronteiras vulneráveis em meio ao silencioso e sorrateiro influxo repugnante da ação leviana. As decisões de cunho coletivo - até individual, passíveis de potenciais danos ao interesse público, não mais se restringiriam as perspectivas internas ou endógenas, contextualizadas perante determinada questão. A nova lógica exigiria profunda sondagem quanto a aspectos como alcance, tipo e teor das ameaças, círculos de pessoas atingidas, efeitos retardados, possíveis responsáveis e repercussão nos casos de demandas por reparação, entre outros ${ }^{16}$.
\end{abstract}

\footnotetext{
$\underline{12}$ Decreto $n^{\circ}$ 1.098/70 - Altera os limites do mar territorial do Brasil e dá outras providências. Revogado pela Lei 8.617/93. Disponível em: 〈http://www.planalto.gov.br/ccivil_03/Decreto-Lei/1965-1988/Del1098.htm> Acesso em: 09 set. 2015.

13 Decreto Legislativo no 05 de 1987 - Aprova o texto da Convenção das Nações Unidas sobre Direito do Mar, concluído em Montego Bay, Jamaica, em 10 de dezembro de 1982. Disponível em: <http://www2.camara.leg.br/legin/fed/decleg/1980-1987/decretolegislativo-5-9-novembro-1987-367281publicacaooriginal-1-pl.html> Acesso em: 09 set. 2015.
}

${ }^{14}$ Decreto 1.530/95 - Declara a entrada em vigor da Convenção das Nações Unidas sobre o Direito do Mar, concluída em Montego Bay, Jamaica, em 10 de dezembro de 1982. Disponível em: <http://www.planalto.gov.br/ccivil_03/decreto/1995/D1530.htm> Acesso em: 09 set. 2015.

${ }^{15}$ MARTINS, Eliane M. Octaviano. Direito marítimo internacional: da responsabilidade internacional pelos danos causados ao meio ambiente marinho. Verba Juris ano 7, n. 7, jan./dez. 2008, p. 261: "A proteção contra a poluição transfronteiriça fundamenta-se nos princípios da interdição do abuso do direito ou, ainda, do princípio da vizinhança internacional. Consagra-se a premissa de que um Estado não poderá sofrer danos por fatos ocorridos em outro Estado. Assim, pode-se dizer, que um Estado que causa poluição cujos efeitos extrapolem suas fronteiras, deverá responder pelos danos causados".

${ }^{16}$ HOGEMANN, Edna Raquel; SANTOS, Marcelo Pereira. Sociedade de risco, bioética e princípio da precaução. In: Revista Veredas do Direito. Belo Horizonte, v. 12, nº 24, p. 125-145, jul/dez. 2015. 


\subsection{ANÁLISE DO REGRAMENTO GERAL DA CONVENÇÃO DE MONTEGO BAY RELATIVO AO DIREITO DO MAR}

Como obrigação geral aos Estados signatários da Convenção, esta determina a proteção e preservação do meio ambiente (art. 192); apresenta medidas visando à prevenção, redução e controle da poluição do meio marinho de modo que os Estados tenham que se esforçar para harmonizar suas políticas a esse respeito (art. 194, 1).

As medidas devem ainda reduzir o tanto quanto possível, nos termos do art. 194,

3:

a) emissão de substancias tóxicas, prejudiciais ou nocivas, especialmente as não degradáveis, provenientes de fontes terrestres, provenientes da atmosfera ou através dela, ou por alijamento;

b) a poluição proveniente de embarcações, em particular medidas para prevenir acidentes e enfrentar situações de emergência, garantir a segurança das operações no mar, prevenir descargas internacionais ou não e regulamentar o projeto, construção, equipamento, funcionamento e tripulação das embarcações;

c) a poluição proveniente de instalações e dispositivos utilizados na exploração ou aproveitamento dos recursos naturais do leito do mar e do seu subsolo, em particular medidas para prevenir acidentes e enfrentar situações de emergência, garantir a segurança das operações no mar e regulamentar o projeto, construção, equipamento, funcionamento e tripulação de tais instalações ou dispositivos;

d) a poluição proveniente de outras instalações e dispositivos que funcionem no meio marinho, em particular medidas para prevenir acidentes e enfrentar situações de emergência, garantir a segurança das operações no mar e regulamentar o projeto, construção, equipamento, funcionamento e tripulação de tais instalações ou dispositivos.

Também constitui regramento geral o dever dos Estados em absterem-se de praticar qualquer ingerência injustificável nas atividades procedidas por outros Estados no exercício de direitos e no cumprimento de deveres nos moldes da Convenção quando da tomada de medidas de prevenção, redução ou controle da poluição do mar (art. 194,4).

Ato contínuo determina a Convenção, que os Estados devem tomar medidas necessárias visando impedir, reduzir ou controlar a poluição do meio marinho, e ainda ter o zelo de evitar a transferência a outros Estados direta ou indiretamente de danos ou riscos de uma zona para outra ou a evitar desenvolver determinada forma de poluição a outra (art. 195).

Referido diploma prevê a obrigatoriedade da notificação de danos iminentes ou reais a demais Estados que possam a vir ser afetado por consequência da poluição, assim como às organizações internacionais respectivas (art. 198).

A Convenção de Montego Bay ainda preceitua sobre planos emergenciais contra a poluição, prevendo a cooperação dos Estados no intuito de prevenir ou reduzir ao mínimo aos danos no meio marinho (art. 199). 
Ainda há a exigência de que os Estados mantenham sob vigilância as consequências de quaisquer procedimentos por eles autorizadas ou a que se dediquem, objetivando determinar se tais atividades são passíveis de poluir o ambiente marítimo (art.

204).

Apresentadas estas premissas gerais de deveres dos Estados signatários referentes à prevenção, redução ou controle da poluição ao meio ambiente marítimo, há ainda a estipulação de obrigações para que se evitem as seguintes formas possíveis de poluição do mar, seja de origem terrestre, poluição proveniente de atividades relativas aos fundos marinhos sob jurisdição nacional, poluição proveniente de procedimentos na Área realizadas por embarcações ou a partir de instalações, estruturas e outros dispositivos que arvorem a sua bandeira ou estejam registrados no seu território, ou operem sob sua autoridade (art. 209), poluição por alijamento, poluição proveniente de embarcações e, por fim, poluição proveniente da atmosfera ou através dela ${ }^{17}$.

Em síntese, a Convenção de Montego Bay (1982) apresenta preceitos dentre outros não menos importantes relativos ao meio ambiente marinho no claro intuito de proteger, prevenir, reduzir ou controlar danos provocados por Estados por meio de suas soberanias, ou em Estados diversos, tentando de forma pacífica a interação dos Estados em busca de uma proteção e preservação efetivas ao ambiente marinho.

\footnotetext{
${ }^{17}$ MATTOS, op. cit., p. 35: No tocante à adoção e execução de leis nacionais e internacionais para prevenir, reduzir e controlar a poluição no meio marinho, a Convenção trata da poluição de origem terrestre, da poluição proveniente de atividades relativas aos fundos marinhos sob jurisdição nacional, da poluição proveniente de atividades na área, da poluição por alijamento, da poluição proveniente de embarcações e da poluição decorrente da atmosfera.
} 


\subsection{MANEIRAS DE POLUIÇÃO DO MAR CONSTANTES DA CONVENÇÃO DE MONTEGO BAY}

Conforme relatado, a Convenção de Montego Bay aborda seis modalidades de poluição do ambiente marinho ${ }^{18}$ no decorrer dos artigos 207 a 212, quando disciplina sobre as normas internacionais e legislação nacional para prevenir, reduzir e controlar a poluição do meio marinho.

Incialmente, no artigo 207, têm-se os preceitos atinentes à poluição de origem terrestre, lembrando-se que sempre referida Convenção atribui aos Estados o dever de determinada ação que, neste caso, constitui em adoção de leis e regulamentos que visem a prevenção, redução ou controle da poluição em ambiente marinho que advêm de fontes terrestres, citando rios, estuários, dutos e instalações de descarga. Preceitua ainda a busca dos Estados pela harmonia da política ao plano regional adequado.

Possibilita aos Estados quando da criação de suas políticas de prevenção, redução ou controle da poluição do meio marinho de origem terrestre buscar produzir normas de caráter geral, levando em consideração as características inerentes a cada região, devendo tais regramentos e normatização serem reavaliados com determinada periodicidade.

Comentando referido artigo, Martins ${ }^{19}$ enfatiza:

As leis, regulamentos, medidas, regras e normas, bem como práticas e procedimentos, devem incluir disposições destinadas a minimizar, tanto quanto possível, a emissão no meio marinho de substancias tóxicas, prejudiciais ou nocivas, especialmente as substâncias não degradáveis.

18 Decreto 1.530/95, op. cit.: “poluição do meio marinho' significa a introdução pelo homem, direta ou indiretamente, de substâncias ou de energia no meio marinho, incluindo os estuários, sempre que a mesma provoque ou possa vir provocar efeitos nocivos, tais como danos aos recursos vivos e à vida marinha, riscos à saúde do homem, entrave às atividades marítimas, incluindo a pesca e as outras utilizações legítimas do mar, alteração da qualidade da água do mar, no que se refere à sua utilização, e deterioração dos locais de recreio."

${ }^{19}$ MARTINS,... op. cit., p. 269. 
No artigo 208, a Convenção trata da poluição proveniente de atividades relativas aos fundos marinhos sob jurisdição nacional. Em meio a suas entrelinhas, também destaca a adoção de leis e regulamentos pelos Estados, contudo direcionado a prevenir, reduzir e controlar as poluições advindas de ilhas artificiais, instalações e estruturas que se encontrem sob sua alçada, adequando estes diplomas ao seu plano regional adequado. Aborda-se no art. 209 o dever de os Estados estabelecerem regras, normas, práticas e procedimentos com recomendação internacional, visando evitar a poluição ao ambiente marinho em decorrência de embarcações, instalações, estruturas, ou quaisquer outros meios que carreguem sua bandeira, que estejam registrados em seu território ou estejam sob seu comando.

No artigo 210, tem-se a poluição por alijamento, estabelecendo os deveres do Estado em adotar medidas, regras, procedimentos, normas, entre outros meios de evitar, reduzir ou controlar a poluição por alijamento. A poluição proveniente de embarcações é tratada no art. 211 , tendo em vista a redução de riscos de acidentes, frisando-se a compulsória notificação de Estados Costeiros, diante da iminência de acidentes que possam ocorrer no litoral ou de interesses conexos.

Por último, a Convenção de Montego Bay aponta a poluição proveniente da atmosfera ou através dela (art. 212), determinando aos Estados a adoção de leis e regulamentos para prevenir, reduzir e controlar a poluição do mar, resultado da atmosfera ou por meio dela, constantes dos espaços aéreos de sua soberania, ou embarcações que arvorem a sua bandeira e embarcações ou aeronaves que encontrem registradas no seu território.

Observa-se que a referida Convenção estipulou que os Estados devem sempre adotar meios e medidas de evitar quaisquer tipos de poluição no ambiente marinho, não somente sobre sua soberania, mas evitar que atinjam a limites de demais Estados,

Em uma breve síntese, Longo ${ }^{20}$ contextualiza:

A Convenção apresenta recomendações para que os organismos internacionais competentes estabeleçam regras, padrões, práticas e procedimentos e que os Estados criem leis e regulamentos para prevenir, reduzir e controlar a contaminação do meio marinho proveniente de todas as fontes (terrestres, de atividades dos fundos marinhos, de lançamentos ou descargas, de navios e da atmosfera), bem como para

\footnotetext{
${ }^{20}$ LONGO, Airton Ronaldo. O debate em busca do consenso - as negociações para os termos finais da Convenção da Jamaica. In: BEIRÃO, André Panno; PEREIRA, Celso Alves; BRASÍLIA, Antônio (orgs.) Reflexões sobre a Convenção do Direito do Mar.,: Funag, 2014. p. 109.
} 
assegurar o cumprimento daqueles procedimentos. Recomenda a cooperação mundial e regional e a assistência técnica na matéria.

De tal forma, compete aos Estados agirem com zelo, objetivando a proteção do ambiente marinho, não somente na extensão pertencente a sua soberania e jurisdição, mas também os dos demais Estados em um verdadeiro sentimento de cooperação mundial, evitando assim a degradação de uma fonte relevante de recursos e riquezas.

\section{INTROITO À RESPONSABILIDADE INTERNACIONAL AMBIENTAL SOBRE DANOS AO MAR}

Dentro do contexto da responsabilidade internacional dos Estados, de maneira clássica e genérica, refere-se à possibilidade de responsabilizar determinado Estado em virtude da queixa de outros Estados, seja acionando os Tribunais Internacionais de Justiça ou Arbitral, ou promovendo um acordo como forma de diplomacia. A responsabilidade estatal constitui um princípio basilar pertinente ao direito internacional, desenvolvido diante da natureza da sistemática jurídica internacional e das doutrinas referentes à soberania e igualdade dos Estados.

Corroborando com o exposto, por este princípio, um Estado comete ato ilícito contra outro Estado, deve ser responsabilizado, ou seja, “a violação de uma obrigação internacional dá origem a uma exigência de reparação." 21

Assim, como a responsabilidade Internacional dentro do contex to apresentado passa a ocupar um segundo plano, Sampaio ${ }^{22}$ explica que "a responsabilidade dos Estados tornouse menos útil para lidar com problemas de cumprimento na área ambiental”, reforçando ainda que esta continua a ter um papel importante na sistemática jurídica internacional, porém que a sanção estatal é ato subsidiário.

\footnotetext{
${ }^{21}$ SHAW, Malcom N. Direito Internacional. Trad. Marcelo Brandão Cipolla, Lenita Ananias do Nascimento, Antônio de Oliveira Sette - Câmara. São Paulo: Martins Martins Fonte, 2010, p. 572.

${ }^{22}$ SAMPAIO, op. cit. p. 07.
} 
Somente para fins elucidativos, a responsabilidade internacional ambiental em geral começou a ser suscitada com o caso de Smelter Trail, na qual Estados Unidos e Canadá estavam em oposição em virtude da poluição advinda do Estado Canadense de dióxido de enxofre, trazendo prejuízo ao Estado Americano. Neste impasse ambiental, o Tribunal Arbitral, em 1941, concluiu pela obrigação estatal de tutelar outros Estados, reconhecendo, neste caso específico, a responsabilização estatal por atos cometidos por sujeitos não estatais, do próprio Estado ou de seus órgãos. ${ }^{23}$

Importante referendar que, somente após a Convenção de Montego Bay, com a corporificação de Convenções anteriores e a delimitação cristalina da ordem conceitual de Zona Econômica Exclusiva ${ }^{24}$, quando o Estado ribeirinho exerce sua soberania e jurisdição nos termos preceituados no instrumento sobre recursos naturais vivos ou não é que foram detectados progressos na questão inerente à responsabilidade dos Estados em prol da proteção do mar.

Nesta linha preventiva, a Declaração do Rio sobre o Meio Ambiente e Desenvolvimento de 1992, referendou a Declaração de Estolcomo e não aviventou como ponto primordial a sanção, almejando a criação de procedimentos de controle efetivo, de brusca reação e informações céleres no caso de poluição, buscando, sobretudo, evitar a proliferação de agentes agressores no ambiente marinho.

\section{Segundo Longo ${ }^{25}$,}

No que diz respeito à preservação do meio marinho, incluída a defesa contra a poluição, procurou-se evitar que os mares e oceanos se transformassem em fontes de preocupação para a humanidade. Assim, todos os Estados têm obrigação de protegê-los e preservá-los e devem tomar medidas adequadas nesse sentido.

De fato, é de enorme valia, conquanto primordial, privar pela prevenção do meio ambiente marinho, mas sem que haja um enfraquecimento das medidas sancionadoras decorrentes da responsabilidade dos Estados, que deve de alguma forma ser penalizado ou punido quando responsável pela poluição do mar, qualquer que seja sua forma.

\footnotetext{
23 SAMPAIO, op. cit. p. 08.

24 MAZZUOLI, op. cit. P. 864: “A chamada zona econômica exclusiva - que constitui uma das principais inovações da Convenção de Montego Bay, que cuida do assunto nos atrs. 55 e seguintes - é a área marítima situada para além do mar territorial adjacente a este, que tem inicio a partir do limite exterior deste último e vai até o limite máximo de 188 milhas marítimas (descontando-se assim as 12 milhas do mar territorial), perfazendo uma extensão máxima de 200 milhas contadas a partir da linha de base normal ou reta, isto é, a partir da costa. Nessa faixa pode o Estado ribeirinho exercer direitos de soberania sobre os recursos naturais vivos e não vivos, bem como jurisdição, de acordo com o que dispõe a Convenção de Montego Bay."

25 LONGO, op. cit. p. 108-109.
} 


\title{
4.1 DA RESPONSABILIDADE INTERNACIONAL DO ESTADO POR DANOS AO MEIO AMBIENTE MARINHO
}

Analisando-se a Seção 9, artigo 235, da Convenção de Montego Bay, verificam-se regras pertinentes à responsabilidade Internacional dos Estados, preceituando que "os Estados devem zelar pelo cumprimento das suas obrigações internacionais relativas à proteção e preservação do meio marinho."

Martins ${ }^{26}$ completa:

\begin{abstract}
Ademais, os Estados devem assegurar através do seu direito interno, meios de recurso que permitam obter uma indenização pronta e adequada ou outra reparação pelos danos resultantes da poluição do meio marinho por pessoas jurídicas, singulares ou coletivas, sob sua jurisdição. A fim de assegurar indenização pronta e adequada por todos os danos resultantes da poluição do meio marinho, os Estados devem cooperar na aplicação do Direito internacional vigente e no ulterior desenvolvimento do Direito internacional relativo às responsabilidades quanto à avaliação dos danos e à sua indenização e à solução das controvérsias conexas, bem como, se for o caso, na elaboração de critérios e procedimentos para o pagamento de indenização adequada, tais como o seguro obrigatório ou fundos de indenização (art. $235,2$ e 3$)$
\end{abstract}

O mecanismo ora definido logicamente é valido somente aos Estados signatários da Convenção, não podendo compelir àqueles que não a aderiram, sob pena de violar o pact sunt servanda. ${ }^{27}$

Logo, Santos, Silveira e Costa ${ }^{28}$ asseveram:

Por mais que exista uma disposição normativa internacional sobre o não cumprimento de suas obrigações por um Estado Parte ou uma organização internacional, com a subsequente implicação de responsabilidade aos mesmos, a sua aplicação efetiva depende imensamente da adesão e do grau de adesão que o Estado demonstra ao tratado internacional. Trata-se de uma questão de colaboração efetiva internacional para evitar desvios praticados por oportunistas que agem no intuito de levar a efeito um célere, mas bastante inseguro, transporte comercial dessas substâncias.

Consequentemente, a ordem de cooperação dos Estados deve estar em harmonia e consonância com a efetivação do direito internacional em vigor, bem como no subsequente desenvolvimento do ramo internacional pertinentes às responsabilidades no que condiz na averiguação dos danos e da correspondente indenização.

No teor ideário da Convenção, direcionam-se "as atividades de investigação, responsabilização e punição dos agentes poluidores, normalmente aos Estados os quais estão normativamente subordinados". ${ }^{29}$

\footnotetext{
26 MARTINS, op. cit., p. 283-284.

27 SOUSA, Amanda Batista; SILVEIRA, Morgana; COSTA, Thaís Medeiros da. A responsabilidade dos Estados no que concerne à poluição marítima em decorrência de derrame de hidrocarbonetos. Direito E-nergia. Ano 5, v. 7, jan - jul 2013, p. 80 - 105.

28 SOUSA, idem, p. 102.

29 SOUSA, op. cit. p. 10.
}

Revista de Pesquisa e Educação Jurídica | e-ISSN: XXXX-XXXX | Minas Gerais | v. 1 | n. 2 | p. 1 - 19 | Jul/Dez. 2015. 
Contudo, em uma análise pormenor, consoante o artigo 232 do instrumento analisado, percebe-se a adoção do critério da responsabilidade civil subjetiva, baseado na ideia de culpa ${ }^{30}$, quando afirma que os Estados serão responsáveis por perdas ou danos que lhes sejam imputáveis, quando decorrer de medidas ilegais.

Martins $^{31}$ afirma que "tal normativa é de ordem interna: os Estados devem estabelecer meios para recorrer aos seus tribunais através de ações relativas a tais perdas e danos".

O tema pertinente à responsabilidade na Convenção de Montego Bay não se esgota na responsabilidade civil, admitindo ainda a responsabilização penal quando prevê a possibilidade da aplicação de penas pecuniárias a infrações às leis e regulamentos nacionais ou mesmo a regras e normas internacionais destinadas a prevenir, reduzir ou controlar a poluição do ambiente marinho ocasionadas por embarcações estrangeiras que se encontrem além do mar territorial $^{32}$, com exceção de ato internacional e grave de poluição.

Uma vez instaurados procedimentos visando a repressão de infrações cometidas por embarcações estrangeiras, prevê a Convenção que, no decurso destas, caso vislumbre a possibilidade de ceder à imposições de sanções, devem ser resguardados os direitos dos acusados.

Interessante referendar que no artigo 231 do instrumento, prevê o dever dos Estados em proceder com a notificação célere do Estado de Bandeira, ou outro Estado que tenha interesse das medidas tomadas relativas às embarcações estrangeiras.

De tal modo, imperioso averiguar quais seriam as formas de reparar os danos causados ao meio ambiente marinho, pois se trata de assunto conexo a responsabilidade internacional.

Inicialmente, tem-se o dever de cumprir com a obrigação internacional, ou seja, uma vez que violou uma obrigação internacional causando danos, não se exime da responsabilidade de continuar a cumprir com a obrigação ora assumida, uma vez possibilitando o contrário, "era quase como se permitisse aos Estados comprar a possibilidade

\footnotetext{
30 RODRIGUES, Silvio. Direito Civil: Responsabilidade Civil. São Paulo: Saraiva, 2006, p. 11: "se diz ser subjetiva a responsabilidade quando se inspira na ideia de culpa, [...] de modo que a prova da culpa do agente causador do dano é indispensável para que surja o dever de indenizar".

31 MARTINS, op. cit., p. 282.

32 Decreto 1.530/95, op. cit.: “A soberania do Estado costeiro estende-se além do seu território e das suas águas interiores e, no caso de Estado arquipélago, das suas águas arquipelágicas, a uma zona de mar adjacente designada pelo nome de mar territorial.”
} 
de violar o Direito Internacional". ${ }^{33}$ Logicamente que o Estado que comete ato ilícito causando prejuízos ao ambiente marinho, tem a obrigação de cessar este fato, adotando de imediato, medidas com intuito de evitar a reincidência.

Um dos meios de reparação que carrega consigo é o dever de reparar o dano, pois, de sua responsabilidade, incumbe ao Estado causador do prejuízo a obrigação de reparação integral do ilícito internacional.

Logo,

\begin{abstract}
Em suma, de um prisma ambiental, para além da obrigação que recai sobre o poluidor para que este tome medidas preventivas, para que cesse as descargas (caso estas subsistam) do material poluente ou substância perigosa, requer-se ainda, ao mesmo, que restaure a situação que existia através da remoção dos elementos poluidores do meio ambiente; que pague a uma entidade privada para que proceda a essa remoção; ou ainda que compense uma entidade pública para que esta o faça. ${ }^{34}$
\end{abstract}

Conforme se extrai, o dever preventivo é inerente à busca pela proteção internacional do meio ambiente, ficando o Estado compelido a reparar os danos causados não somente no seu território e jurisdição, como também os danos causados aos demais Estados, buscando restaurar o status ante quo.

Outra fonte de medida reparadora é a restituição em espécie, consistente em restituir ao Estado acometido pelo dano causado por Estado diverso, eliminado todo e qualquer efeito gerado pelo ato ilícito, exceto quando a restituição configure medida impossível ou torne-se por demais desproporcional frente à serventia conseguinte do recurso à restituição em vez da compensação. ${ }^{35}$

A indenização é cabível quando impossível a restitutio in integrum, assim cabível a indenização em prestação pecuniária proporcional ao dano, ou seja, nem inferior, nem exorbitante, também conhecida como reparação por equivalência, e amplamente utilizada quando do acometimento de danos internacionais ambientais. A compensação financeira deve abranger o dano que se pode mensurar e incluir os lucros cessantes.

Há de se falar também da medida reparadora satisfação, possuindo um conteúdo moral, buscando por meio desta a restauração da dignidade soberana do Estado afetado e ainda a reestruturação do sentimento de respeito próprio do Estado, cabível quando não há como reparar os danos por meio de compensação ou restituição.

\footnotetext{
${ }^{33}$ SAMPAIO, op. cit., p. 30.

${ }^{34}$ SAMPAIO, op. cit., p. 33.

${ }^{35}$ SAMPAIO, op.cit., p. 34.
} 


\subsection{FORMAS DE EFETIVAÇÃO DA RESPONSABILIDADE AMBIENTAL INTERNACIONAL À LUZ DA CONVENÇÃO DE MONTEGO BAY}

Buscando efetivar a responsabilidade ambiental internacional, à guisa da Convenção de Montego Bay, foi conferida a um Tribunal a competência de dirimir controvérsias quando estas não são resolvidas extrajudicialmente por negociação ${ }^{36}$, bons ofícios ${ }^{37}$, mediação ${ }^{38}$, inquérito $^{39}$ e conciliação ${ }^{40}$ como regras existentes no Direito Internacional como um todo.

O Tribunal possui jurisdição internacional, conferida pelos Estados signatários da Convenção de Montego Bay, denominado Tribunal Internacional do Direito do Mar, salientando-se que o acesso a esta instância se estende aos Estados não signatários da Convenção, diferenciado dos demais Tribunais Internacionais existentes ${ }^{41}$.

Compete a este Tribunal, estabelecido em Hamburgo, julgar os conflitos atinentes ao Direito do Mar, bem como a aplicação e interpretação da Convenção de Montego Bay além de possuir competência consultiva emitindo pareceres sobre acordos realizados.

Composto por 21 membros independentes, eleitos, com notável conhecimento de direito do mar, imparciais e íntegros, o Tribunal possui também a competência para constituir

\footnotetext{
36 SAMPAIO, op. Cit., p. 42: “A negociação é a técnica mais antiga e habitual de resolver as controvérsias internacionais219, e é não apenas importante no âmbito da resolução de litígios, como ainda ao nível da cooperação internacional e da criação de Direito Internacional, nos mais variados sectores, possuindo uma natureza costumeira."

37

SAMPAIO, op. cit., p. 44: "[...] estes não «constituem exactamente um meio directo de resolução pacífica, mas um meio de conseguir que as partes recorram ao anterior, a negociação. Este meio envolve a participação de uma entidade terceira - apesar de ainda não se poder falar de mediação - que procura aproximar as partes, convencendo-as a negociar diretamente (sic) de modo a resolver a sua controvérsia. Todavia, «este terceiro não chega depois a participar nas negociações, visando a sua acção (sic) o início ou o restabelecimento de um procedimento de negociações"

38 SAMPAIO, op. cit., p. 44: “A mediação consiste num método de resolução pacífica de disputas internacionais em que um terceiro - por exemplo, um Estado, uma organização internacional ou um indivíduo - intervém para procurar reconciliar as partes em contenda e avançar as suas próprias propostas, com o objetivo(sic) de alcançar uma solução aceitável de compromisso mútuo".

39

9 SAMPAIO, op. cit., p. 46: "Este meio realiza-se através do recurso a uma ou mais entidades terceiras (que, neste segundo caso, formarão uma comissão de inquérito), com o objectivo (sic) de apurar determinados factos (sic) cuja ocorrência, características ou responsabilidade divide as partes numa controvérsia".

40 SAMPAIO, op. cit., p. 47: "método para a resolução de disputas internacionais de qualquer natureza, de acordo com a qual uma comissão estabelecida pelas partes (...) procede à examinação imparcial da disputa e procura definir os termos de um acordo susceptível de ser aceite ou proporcionado pelas partes, de forma a resolver a referida disputa, contribuindo com toda a ajuda que possa ter sido requerida".

41 Tribunal Internacional del Derecho del Mar. Hamburgo: Oficina de Prensa, 2011, p. 04: "También tienen acceso al Tribunal las entidades distintas de los Estados Partes, esto es, los Estados u organizaciones intergubernamentales que no sean partes en la Convención y las empresas estatales y entidades privadas". Disponível em: <https://www.itlos.org/fileadmin/itlos/documents/brochure /ITLOS_Brochure_spanish.pdf> Acesso em 14 set. 2015.
} 
Câmaras, nos termos constantes de seu Estatuto quando entender necessário que conheceram de certas categorias de controvérsias.

De tal modo, convém especificar que a sentença exarada pelo Tribunal tem caráter definitivo, devendo ser acatada na íntegra pelas partes presentes na controvérsia. Dessa forma, a jurisprudência sedimentada contribui para o desenvolvimento de um entendimento normativo que serve de direcionamento para as demais decisões a serem exaradas em âmbito do direito internacional.

$$
\text { Logo, Menezes }{ }^{42} \text { : }
$$

As lides foram protagonizadas entre Estados de diferentes continentes, denotando o Direito do Mar como um direito da humanidade, de caráter universal e transnacional e tema recorrente na contemporaneidade, em que os espaços transnacionais são regidos por uma jurisdição comum. É de se destacar a diversidade de mecanismos acionados pelos Estados em litígio, desde opiniões consultivas, passando por contraditório envolvendo liberação de embarcações, caução, pavilhão e nacionalidade de navio, delimitação territorial, controle de pesca, práticas ilegais, imunidade de jurisdição, extensão de responsabilidades e, em alguns momentos, dispositivos normativos adotados pela própria legislação dos Estados.

Ressalta-se assim a consolidação das jurisprudências em âmbito internacional, relativos ao Direito do Mar e a importância da atuação do Tribunal do Direito do Mar para dar efetividade na busca da prevenção de danos ao ambiente marinho com a correta aplicação e interpretação das normas internacionais, assim como meio de efetivar as responsabilidades caso não consiga dirimir as lides por meios extrajudiciais.

${ }^{42}$ MENEZES, Wagner. Tribunal Internacional Do Direito Do Mar E Sua Contribuição Jurisprudencial In: BEIRÃO, André Panno; PEREIRA, Antônio Celso Alves (orgs). Reflexões sobre a Convenção do Direito do Mar. Brasília: Funag, 2014. p. 513. 


\section{CONCLUSÃO}

Não há como imaginar uma convivência e uso pacífico de um complexo geográfico único, composto pelos mares e oceanos, sem que haja uma parcimônia, harmonia e cooperação dos Estados com suas soberanias e jurisdições individuais.

De fato, a criação de um direito internacional objetivando proteger o ambiente marinho é uma necessidade emergente, resultante desta consciência da importância vital para sobrevivência humana, economia global, transporte, entre outros meios de utilidade deste todo geográfico. Trata-se de desejo de tutelar o meio ambiente marinho, trazendo como preocupação primordial as ações de caráter preventivo, almejando eliminar danos, ficando em segundo plano as responsabilizações estatais por fatos ilícitos que provoquem danos ao mar.

Um marco primordial de desenvolvimento da legislação internacional do direito do Mar é a Convenção de Montego Bay, que cria mecanismos em prol da prevenção, controle e reparação de danos causados ao ambiente marinho pelos Estados, ensejando o retorno do ambiente a seu status quo, a indenização do Estado prejudicado entre outras obrigações decorrentes do fato ilícito.

De tal modo, há meios de efetivar a responsabilização do Estado por danos provocados ao mar, podendo ser de maneira diplomática por conciliação, negociação, bons ofícios, mediação, extrajudicial como o inquérito, ou judicialmente utilizando-se do Tribunal Internacional do Direito do Mar, que profere sua decisão, compelindo às partes a acatar na íntegra o que foi decidido.

Ainda bem distante da completude, pois nem todos os Estados são signatários da Convenção de Montego Bay, a legislação internacional do mar é um enorme avanço em prol da tutela universal do ambiente marinho e meio necessário para um ambiente sustentável que deve ser preservado e protegido diante de sua infinita importância para a vida terrestre em todos seus aspectos.

\section{REFERÊNCIAS}

BOBBIO, Norberto. A Era dos Direitos. Tradução: Carlos Nelson Coutinho. Apresentação: Celso Lafer. Rio de Janeiro: Elsevier, 2004.

BRASIL. Decreto Legislativo no 05 de 1987 - Aprova o texto da Convenção das Nações Unidas sobre Direito do Mar, concluído em Montego Bay, Jamaica, em 10 de dezembro de 1982. Disponível em: <http://www2.camara.leg.br/legin/ fed/decleg/1980- 
1987/decretolegislativo-5-9-novembro-1987-367281-publicacaooriginal-1-pl.html> Acesso em: 09 set. 2015.

Decreto Legislativo $\mathbf{n}^{\circ} 1.098$ de 1970 - Altera os limites do mar territorial do Brasil e dá outras providências. Revogado pela Lei 8.617/93. Disponível em: <http://www.planalto.gov.br/ccivil_03/Decreto-Lei/1965-1988/Del1098.htm> Acesso em: 09 set. 2015.

. Decreto Legislativo no 1.530 de 1995 - Declara a entrada em vigor da Convenção das Nações Unidas sobre o Direito do Mar, concluída em Montego Bay, Jamaica, em 10 de dezembro de 1982. Disponível em: <http://www.planalto.gov.br/ ccivil_03/decreto/1995/D1530.htm> Acesso em: 09 set. 2015.

. Lei n⿳ 8.617/93 - Dispõe sobre o mar territorial, a zona contígua, a zona econômica exclusiva e a plataforma continental brasileiros, e dá outras providências. Disponível em: <http://www.planalto.gov.br/ccivi 1_03/LEIS/ L8617.htm> Acesso em: 09 set., 2015. HOGEMANN, Edna Raquel; SANTOS, Marcelo Pereira. Sociedade de risco, bioética e princípio da precaução. In: Revista Veredas do Direito. Belo Horizonte: Dom Helder - Escola do Direito, v. 12, nº 24, p. 125-145, jul/dez. 2015.

LONGO, Airton Ronaldo. O debate em busca do consenso - as negociações para os termos finais da Convenção da Jamaica. In: Reflexões sobre a Convenção do Direito do Mar. André Panno Beirão, Antônio Celso Alves Pereira. (orgs.). Brasília: Funag, p. 67 - 126. 2014.

MARTINS, Eliane M. Octaviano. “Amazônia Azul”: limites e extensão das zonas marítimas sob soberania e jurisdição nacional do Brasil. Meritum - v. 02, nº 02, p. 265-279. Jul/dez. 2007. Belo Horizonte.

MARTINS, Eliane M. Octaviano. Direito marítimo internacional: da responsabilidade internacional pelos danos causados ao meio ambiente marinho. Verba Juris. Ano 7, n. 7, jan./dez. 2008.

MATTOS, Adherbal Meira. Os novos limites dos espaços marítimos nos trinta anos da Convenção das Nações Unidas sobre o Direito do Mar. In: Reflexões sobre a Convenção do Direito do Mar. André Panno Beirão, Antônio Celso Alves Pereira. (organizadores). Brasília: Funag. Pág. 21-66. 2014.

MAZZUOLI, Valério de Oliveira. Direito Internacional Público. 9 ed. Ver. ampl. - São Paulo: Editora Revista dos Tribunais, 2015. 
MENEZES, Wagner. Tribunal Internacional Do Direito Do Mar E Sua Contribuição Jurisprudencial In: Reflexões sobre a Convenção do Direito do Mar. André Panno Beirão, Antônio Celso Alves Pereira. (organizadores). Brasília: Funag. Pág. 489 - 571. 2014. ORGANIZAÇÃO DAS NAÇÕES UNIDAS - Convenção sobre o Direito do Mar - Convenção de Montego Bay (1982). In: MAZZUOLI, Valério de Oliveira (org.) Coletânea de Direito Internacional. 10 ed. São Paulo: Editora Revista dos Tribunais, 2012. SOUSA, Amanda Batista; SILVEIRA, Morgana; COSTA, Thaís Medeiros da. A responsabilidade dos Estados no que concerne à poluição marítima em decorrência de derrame de hidrocarbonetos. Direito E-nergia. Ano 5, v. 7, jan - jul 2013, p. 80 - 105. 